\title{
Novel Links between TORC1 and Traditional Non-Coding RNA, tRNA
}

\author{
Yoko Otsubo ${ }^{1,2,3}$ (D), Yoshiaki Kamada ${ }^{1,4}$ and Akira Yamashita $1,3,4, *$ (D) \\ 1 National Institute for Basic Biology, Nishigonaka 38, Myodaiji, Okazaki, Aichi 444-8585, Japan; \\ otsubo@nibb.ac.jp (Y.O.); yoshikam@nibb.ac.jp (Y.K.) \\ 2 National Institute for Fusion Science, 322-6 Oroshi, Toki, Gifu 509-5292, Japan \\ 3 Center for Novel Science Initiatives, National Institutes of Natural Sciences, Nishigonaka 38, Myodaiji, \\ Okazaki, Aichi 444-8585, Japan \\ 4 Department of Basic Biology, School of Life Science, SOKENDAI (The Graduate University for \\ Advanced Studies), Nishigonaka 38, Myodaiji, Okazaki, Aichi 444-8585, Japan \\ * Correspondence: ymst@nibb.ac.jp
}

Received: 30 July 2020; Accepted: 17 August 2020; Published: 19 August 2020

\begin{abstract}
Target of rapamycin (TOR) is a serine/threonine kinase that modulates cell growth and metabolism in response to environmental changes. Transfer RNA (tRNA) is an abundant and ubiquitous small non-coding RNA that is essential in the translation of mRNAs. Beyond its canonical role, it has been revealed that tRNAs have more diverse functions. TOR complex 1 (TORC1), which is one of the two TOR complexes, regulates tRNA synthesis by controlling RNA polymerase III. In addition to tRNA synthesis regulation, recent studies have revealed hidden connections between TORC1 and tRNA, which are both essential players in eukaryotic cellular activities. Here, we review the accumulating findings on the regulatory links between TORC1 and tRNA-particularly those links in the budding yeast Saccharomyces cerevisiae and the fission yeast Schizosaccharomyces pombe.
\end{abstract}

Keywords: TORC1; tRNA; budding yeast; fission yeast

\section{TORC1 and tRNA}

Target of rapamycin (TOR) is a highly conserved serine/threonine kinase among eukaryotes. TOR acts as a master regulator that controls cell growth and metabolism in response to environmental changes (reviewed in [1,2]). TOR forms two distinct multi-protein complexes-TOR complex 1 (TORC1), and complex 2 (TORC2) - which regulate a variety of cellular activities. Between these, only TORC1 is sensitive to rapamycin. The activity of TORC1 is regulated by nutrients, growth factors, and cellular energy. In mammals, growth factors and cellular energy stimulate the activity of mTORC1 through Rheb GTPase, and via the inhibition of the tuberos sclerosis complex (TSC), which functions as a GTPase-activating protein for Rheb. When responding to the availability of amino acids, mTORC1 is activated via RAG GTPases in a TSC-independent pathway. Under nutrient-rich conditions, TORC1 promotes anabolic processes, such as protein, nucleotide, and lipid synthesis, while inhibiting catabolic processes, such as autophagy.

Transfer RNAs (tRNAs) are abundant, small, and ubiquitous non-coding RNAs that are essential for decoding genetic information, achieving this by delivering amino acids to the growing polypeptide chains in ribosomes. Each tRNA is charged with a cognate amino acid on its $3^{\prime}$ end, in an ATP-dependent manner. This process is catalyzed by aminoacyl-tRNA synthetases (ARSs). Each aminoacyl-tRNA is brought to the A-site of the ribosome by the translation elongation factor $1 \mathrm{~A}$; then, its anticodon forms base pairs with a corresponding mRNA codon. In recent years, a growing number of reports have shown that tRNAs have a wide range of cellular functions beyond their canonical role as 
adaptor molecules during protein synthesis [3-5]. For example, tRNA-derived small RNAs have been extensively studied and demonstrated to be novel, functional, non-coding RNAs (reviewed in [6,7]). tRNA is an essential biomolecule during translation, and TORC1 participates in the regulation of translation, suggesting a promising relationship between tRNA and TORC1. In fact, accumulating reports have demonstrated the involvement of tRNA, and its related factors, in the TORC1 pathway. In this review, we highlight recent findings on the TORC1-related roles of tRNA, and its related factors, in the budding yeast Saccharomyces cerevisiae and the fission yeast Schizosaccharomyces pombe, both of which have contributed to our understanding of the cellular signaling pathway, including TOR signaling.

\section{2. tRNA-Mediated Inactivation of TORC1 in S. cerevisiae}

In mammalian cells, the Rag complex, which is composed of RagA/RagB and RagC/RagD, regulates TORC1 by responding to amino acid levels. Rag proteins are conserved in S. cerevisiae, and the counterparts of $\operatorname{RagA} / \operatorname{RagB}$ and $\operatorname{Rag} C / \operatorname{RagD}$ are Gtr1 and Gtr2, respectively [8-10]. The S. cerevisiae genes that encode the Rag proteins, namely GTR1 and GTR2, are nonessential; this suggests that the Rag system is not the sole pathway to amino acid sensing by TORC1. In a study wherein the alternative mechanisms underlying the TORC1 regulation were elucidated, the tRNA-mediated inactivation of TORC1 in S. cerevisiae was demonstrated [11].

tRNA severely inhibits in vitro TORC1 activity. The inactivation of RNA polymerase III, which transcribes tRNA, results in the maintenance of TORC1 activity upon starvation. From these observations, it has been proposed that amino acid starvation increases the number of free uncharged tRNA that is liberated from protein synthesis; then, the accumulated free tRNA inactivates TORC1 (Figure 1). The result, that TORC1 activity is impaired in ARS mutants, supports this attractive model. tRNA may be the best player to monitor amino acid levels as it enables a response to the shortage in all kinds of amino acids.
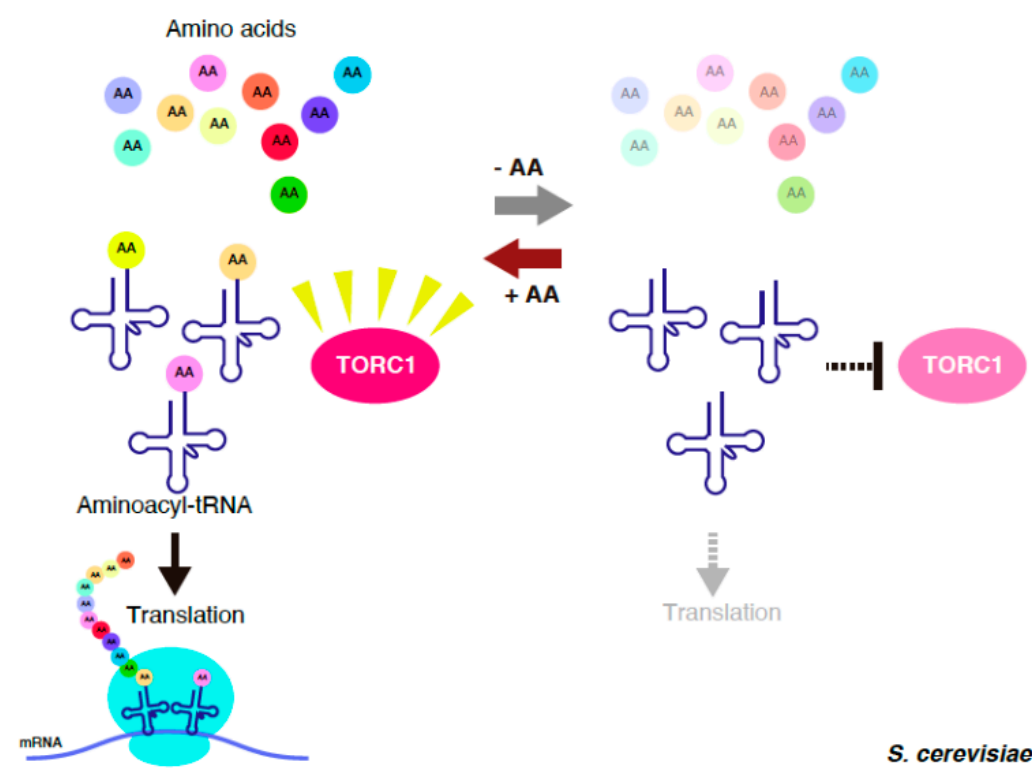

S. cerevisiae

Figure 1. Transfer RNA (tRNA)-mediated target of rapamycin complex 1 (TORC1) regulation in Saccharomyces cerevisiae. Under amino acid-rich conditions, tRNAs are charged with cognate amino acids, and the resultant aminoacyl-tRNAs are delivered to the ribosome for translation. Upon amino acid starvation, free uncharged tRNAs increase, and the accumulated free tRNAs inactivate TORC1.

\section{3. tRNA Precursor-Mediated TORC1 Regulation in S. pombe}

The synthesis of tRNAs involves several steps of post-transcriptional processing. These events include the removal of the $5^{\prime}$ leader, processing of the $3^{\prime}$ trailer, splicing of introns, addition 
of the $3^{\prime}$-terminal CCA residues, and modification of multiple nucleoside residues. In S. pombe, TORC1 represses sexual differentiation and exerts an essential function for vegetative growth, via a nutrient-sensing pathway [12-16], while TORC2 is required for sexual differentiation [17-19]. The temperature-sensitive mutants of tor2, which encodes the catalytic subunit of S. pombe TORC1, induce an ectopic initiation of sexual differentiation, even under nutrient-rich conditions at non-permissive temperatures. Several mutants that phenocopy the TORC1 mutant have been isolated. Intriguingly, many of their responsible genes encode factors that are involved in tRNA expression and modification, such as ARSs, a subunit of RNA polymerase III, or a tRNA specific adenosine deaminase subunit [20]. TORC1 activity is downregulated in these tRNA-related mutants; this suggests that tRNA may be involved in TORC1 regulation in S. pombe. The observation that the overexpression of tRNA precursors prevents TORC1 downregulation upon nutrient starvation and inhibits sexual differentiation indicates that tRNA precursors regulate TORC1 activity in a positive manner (Figure 2). Consistently, the expression of tRNA precursors drastically decreases with nutrient depletion. Moreover, nutrient starvation does not significantly affect the level of aminoacylation and the total amount of tRNA [20]. Although precise mechanisms on how tRNA precursors regulate the TORC1 activity remain unknown, Gtr1, a counterpart of RagA/B, is dispensable for tRNA precursor-mediated TORC1 regulation [20]. Notably, S. pombe Rag GTPases negatively regulate TORC1 activity in contrast to the mammalian Rag complex [21,22].

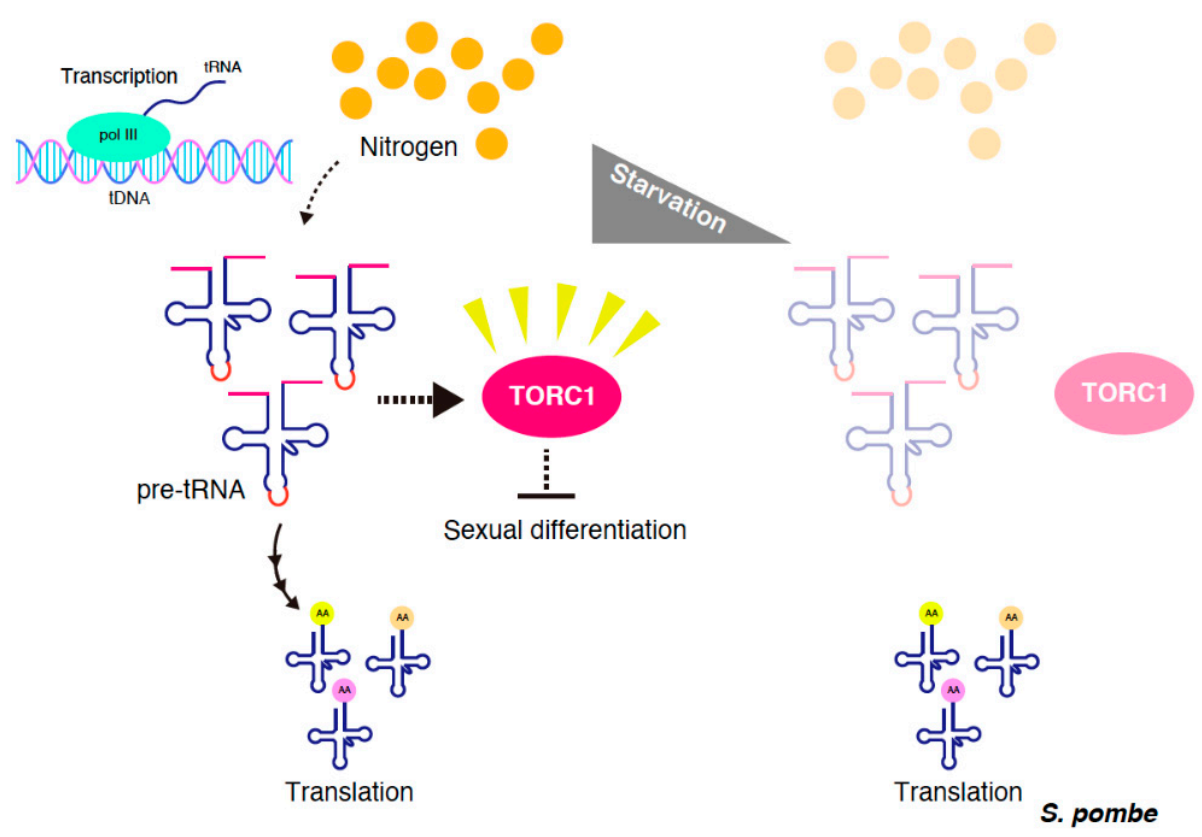

Figure 2. tRNA precursor-mediated TORC1 regulation in Schizosaccharomyces pombe. Under nitrogen-rich conditions, tRNA precursors positively regulate TORC1 activity. Under nitrogen-starved conditions, the expression of tRNA precursors decreases, resulting in the inactivation of TORC1.

\section{4. tRNA Modification and TORC1}

Rapamycin has no impact on the cell growth of $S$. pombe wild-type cells, whereas mutants with reduced TORC1 activity are sensitive to rapamycin $[13,23,24]$. In a genetic screening for rapamycin sensitive mutants, the genes involved in tRNA modification were identified as those with the highest enrichment [25] (Table 1), thereby suggesting a close relationship between tRNA modification and TORC1. Among all types of cellular RNAs, tRNAs undergo highly diverse post-transcriptional modifications [26,27]. tRNA modifications are vital for the folding, stability, and function of tRNAs [5,28-30]; these modifications are found on approximately $12 \%$ of the residues of all sequenced 
tRNAs from a wide range of organisms [31]. Furthermore, more than 100 tRNA modifications have been discovered according to the MODOMICS database (http://genesilico.pl/modomics/) [32].

tRNA modifications occur most frequently within the anticodon loop, especially at positions 34 and 37. Position 34, which is the so-called wobble position, pairs with a third mRNA codon base, in the A-site of the ribosome, during translation [33]. A uridine base at the wobble position, U34, is carboxymethylated by the highly conserved Elongator complex [30,34-37].

Table 1. tRNA-modification genes whose deletion causes rapamycin sensitivity in S. pombe.

\begin{tabular}{ccc}
\hline Systematic ID & Gene Name & Product \\
\hline SPAC30C2.04 & asc1 & Cofactor for cytoplasmic methionyl-and glutamyl-tRNA synthetases \\
SPBC2G5.03 & ctu1 & Cytosolic thiouridylase subunit \\
SPAC25B8.05 & deg1 & tRNA-pseudouridine synthase \\
SPBC36.07 & elp1 & Elongator complex WD repeat protein \\
SPAC29A4.20 & elp3 & Elongator complex tRNA uridine (34) acetyltransferase subunit \\
SPCC11E10.06c & elp4 & Elongator complex subunit \\
SPBC3H7.10 & elp6 & Elongator complex subunit \\
SPAC30.02c & kti12 & Elongator complex associated protein \\
SPAC57A10.10c & sla1 & La protein, tRNA chaperone \\
SPBP8B7.09c & los1 & Karyopherin/importin- $\beta$ family nuclear import receptor \\
\hline
\end{tabular}

Interestingly, in S. pombe, mutant strains that lack the Elongator complex subunits show exaggerated sensitivity to rapamycin $[25,38]$ (Table 1 ). The deletion of the genes that encode the Elongator subunits results in the lower expression of TORC1 repressors, such as Tsc1 and Tsc2 [39]. Furthermore, the overexpression of tor 2 , which encodes the catalytic subunit of $S$. pombe TORC1, increases the sensitivity to rapamycin. This observation suggests that the hyperactivation of TORC1 leads to a higher sensitivity to rapamycin, as in the case of the downregulation of TORC1 activity, even though there may be a possibility that the overexpression of the catalytic subunits results in the downregulation of TORC1 by perturbing the balance of the components. From these observations, it is concluded that Elongator contributes to the downregulation of TORC1 by promoting the expression of repressors, such as Tsc1 and Tsc2. The positive regulation of TORC2 by Elongator has also been proposed [39].

The participation of tRNA modification in TORC1 regulation has been found in S. cerevisiae; however, its effect on TORC1 is opposite in both yeasts. In S. cerevisiae, the Elongator mutant cells have been shown to exhibit hypersensitivity to rapamycin [40-42]. Moreover, in the tRNA anticodon loop modification mutants (e.g., a double mutant of modification factors at positions 34 and 37), starvation responses, such as the starvation-responsive gene expression and autophagy, which are prevented by TORC1, are untimely observed under nutrient-rich conditions [43]. This implies that tRNA modification acts positively on TORC1 (Figure 3). While many of the TORC1 regulators are conserved in S. cerevisiae and S. pombe, there are differences. For instance, S. cerevisiae does not have homologs of TSC1 and TSC2. Thus, it is rational that the roles of tRNA modification in TORC1 signaling differ between two yeast species.

Rapamycin cannot prevent the growth of S. pombe [23]. However, the simultaneous treatment of rapamycin and caffeine, the latter of which is also known to decrease TORC1 activity [44,45], inhibits S. pombe growth [46]. Gene expression profiling was performed, after the combined treatment of rapamycin and caffeine, using DNA microarrays [47]. We surveyed the genes that are upregulated or downregulated by more than three-fold after treatment with rapamycin and caffeine, and selected the genes related to the tRNA metabolic pathway or the tRNA binding in an S. pombe database, PomBase (https://www.pombase.org). Shown in Tables 2 and 3 are the tRNA-related genes that are upregulated or downregulated, via the inactivation of TORC1. Further studies of these genes would shed light on the roles of $t R N A-$ related factors in the TORC1 pathway. 


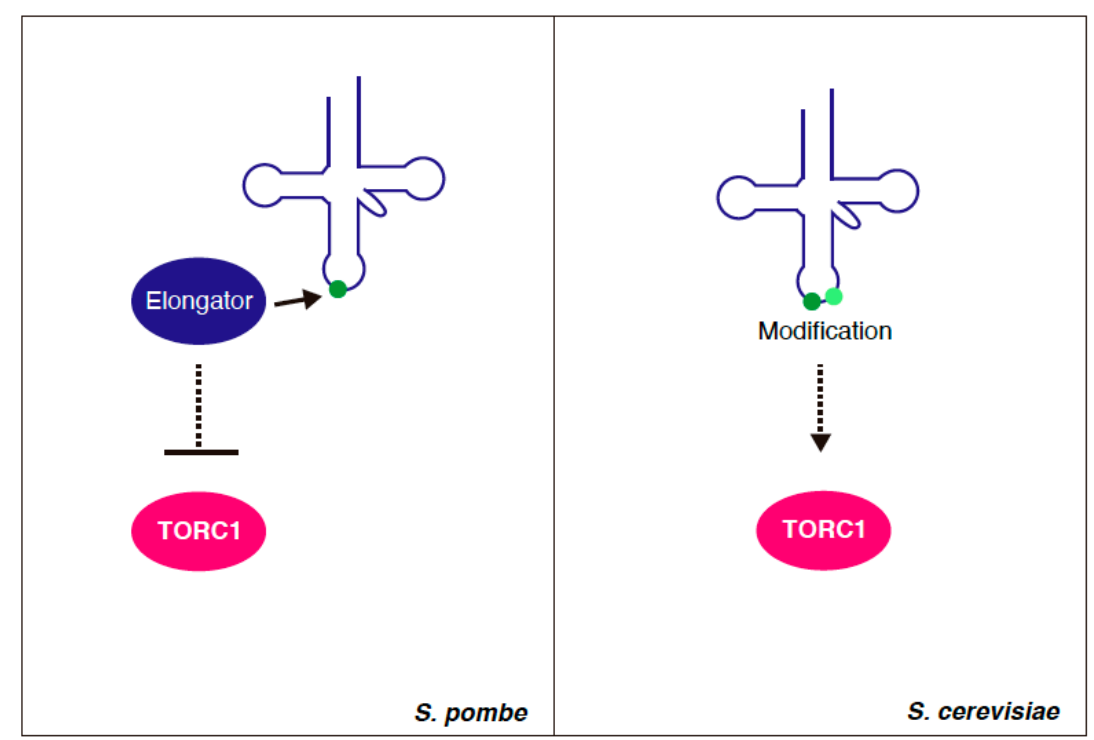

Figure 3. tRNA modification and TORC1. In Schizosaccharomyces pombe, Elongator, which catalyzes modification of the wobble base, negatively regulates TORC1. In Saccharomyces cerevisiae, tRNA modification acts positively on TORC1.

Table 2. tRNA-related S. pombe genes upregulated more than three-fold after treatment with rapamycin and caffeine.

\begin{tabular}{cccc}
\hline Systematic ID & Gene Name & Product & Viability of Deletion Mutant \\
\hline SPBC16D10.10 & tad2 & tRNA specific adenosine deaminase subunit & inviable \\
\hline SPCC4B3.01 & tum1 & $\begin{array}{c}\text { Thiosulfate sulfurtransferase, involved in } \\
\text { tRNA wobble position thiolation }\end{array}$ & unknown \\
\hline
\end{tabular}

Table 3. tRNA-related $S$. pombe genes downregulated more than three-fold after treatment with rapamycin and caffeine.

\begin{tabular}{|c|c|c|c|}
\hline Systematic ID & Gene Name & Product & Viability of Deletion Mutant \\
\hline SPAC9G1.12 & cpd1 & $\begin{array}{l}\text { tRNA (m1A) methyltransferase complex } \\
\text { catalytic subunit }\end{array}$ & viable \\
\hline SPAC20G8.09c & nat10 & rRNA/tRNA cytidine N-acetyltransferase & depends on conditions \\
\hline SPCC126.03 & pus1 & $\begin{array}{l}\text { TruA family tRNA/U2 snRNA } \\
\text { pseudouridine synthase }\end{array}$ & viable \\
\hline SPAC22A12.05 & $\operatorname{rpc11}$ & $\begin{array}{l}\text { DNA-directed RNA polymerase III } \\
\text { complex subunit }\end{array}$ & inviable \\
\hline SPAC57A10.10c & sla1 & La protein, tRNA chaperone & viable \\
\hline SPBC16D10.02 & $\operatorname{trm} 11$ & $\begin{array}{l}\text { tRNA (guanine-N2-)-methyltransferase } \\
\text { catalytic subunit }\end{array}$ & viable \\
\hline SPAC31A2.02 & $\operatorname{trm} 112$ & $\begin{array}{l}\text { eRF1 methyltransferase complex and } \\
\text { tRNA (m2G10) methyltransferase } \\
\text { complex regulatory subunit }\end{array}$ & viable \\
\hline SPCPB16A4.04c & trm8 & $\begin{array}{l}\text { tRNA (guanine-N7-)-methyltransferase } \\
\text { catalytic subunit }\end{array}$ & viable \\
\hline SPCC18.13 & $\operatorname{trm} 82$ & $\begin{array}{l}\text { tRNA (guanine-N7-)-methyltransferase } \\
\text { WD repeat subunit }\end{array}$ & viable \\
\hline
\end{tabular}




\section{5. tRNA Nuclear Transport and TORC1}

As mentioned above, tRNAs are synthesized as tRNA precursors (pre-tRNAs) prior to the post-transcriptional modifications. In S. cerevisiae, intron-containing pre-tRNAs are exported from the nucleus to the cytoplasm for the removal of introns, and the spliced tRNAs return to the nucleus via a so-called tRNA retrograde transport [48,49]. Amino acid starvation induces a nuclear accumulation of spliced tRNAs [48]; this suggests the involvement of TORC1 in tRNA retrograde transport. Two independent studies have demonstrated the link between TORC1 and tRNA retrograde transport [50,51]; however, the detailed mechanisms are yet to be addressed. Whitney et al. showed that rapamycin treatment during amino acid starvation prevents the nuclear accumulation of spliced tRNA, whereas the treatment with rapamycin under nutrient-rich conditions does not induce the nuclear tRNA accumulation [50]. This suggests that TORC1 plays a crucial role in tRNA accumulation during amino acid starvation. Pierce et al. demonstrated that the inhibition of TORC1 by rapamycin results in the nuclear accumulation of spliced tRNAs even in nutrient-rich conditions, thus implying that TORC1 regulates the nuclear re-export of retrograde transported spliced tRNAs [51]. Therefore, the role of TORC1 in tRNA localization must be clarified in further studies.

Notably, the S. pombe mutant cells that were lacking Los1, which is a nuclear tRNA export receptor, showed sensitivity to rapamycin [25] (Table 1). There may be a relationship between TORC1 and the regulation of the tRNA localization in $S$. pombe.

\section{6. tRNA Synthesis by RNA Polymerase III and TORC1}

Eukaryotes have three major RNA polymerases: Pol I, II, and III. tRNAs are synthesized by Pol III [52,53]. Pol III activity is regulated in response to diverse extracellular signals. Moreover, the rapid repression of RNA pol III-dependent transcription ensures cellular survival against environmental stress. TORC1 regulates pol III transcription by controlling Maf1, which is the evolutionarily conserved repressor of pol III. Here, we present a brief overview of the TORC1-mediated regulation of Maf1. For more details on the function and regulation of Maf1, please refer to other excellent reviews [54-57].

Maf1 represses pol III-dependent transcription during the various stress conditions, including nutrient starvation, rapamycin treatment, and DNA damage [58,59]. Maf1 is phosphorylated during normal growth conditions. Under stress conditions, Maf1 is dephosphorylated; this leads to the nuclear import of Maf1. Subsequently, Maf1 in the nucleus binds to pol III and represses pol III activity [60-62]. The phosphorylation of Maf1 is largely mediated by the TORC1 pathway. While mammalian Maf1 is phosphorylated by mTORC1, S. cerevisiae Maf1 is mainly phosphorylated by the Sch9 kinase, which is a target of TORC1 [63-67]. The direct phosphorylation of S. cerevisiae Maf1 by TORC1 has been observed, at least in vitro [68]. In S. pombe, the phosphorylation of Maf1 has been reported to be dependent on TORC1; however, whether TORC1 is directly involved or not remains unclear [69].

In S. cerevisiae, TORC1 also regulates tRNA synthesis through the LAMMER/Cdc-like kinase Kns1 and casein kinase II CK2 [70]. Kns1 is negatively regulated downstream of TORC1. When TORC1 is inhibited, the activated Kns1 phosphorylates Ckb1, which is a CK2 regulatory subunit. This causes a reduction in the CK2 occupancy of the tRNA genes, and results in the repression of pol III. Kns1 also phosphorylates Rpc53, a pol III subunit [71]; the significance of this phosphorylation remains unknown.

In S. cerevisiae, several subunits of pol III, including Rpc82, Rpc53, and Ret1, are sumoylated in a TORC1-dependent manner. The sumoylation of Rpc82 contributes to the stabilization of the pol III complex and is required for an efficient tRNA transcription under optimal growth conditions [72].

A recent study has shown an interesting relationship between pol III and the longevity downstream of TORC1 in S. cerevisiae, the fly, and nematode [73]. A reduction in pol III activity has been reported to result in the expansion of the chronological lifespan of S. cerevisiae. In S. pombe, the downregulation of TORC1 upon nutrient starvation causes the activation of the GATA transcription factor Gaf1 [74]. Recently, Gaf1 has been shown to bind tRNA genes and repress their transcription, thereby leading to the extension of the chronological lifespan [75]. 


\section{Leucyl-tRNA Synthetase and TORC1}

In mammals and S. cerevisiae, the heterotrimeric protein complexes GATOR1 and SEACIT function as GTPase-activating proteins for RagA/RagB and Gtr1, respectively. GATOR2 and SEACAT bind to and negatively regulate GATOR1 and SEACIT. In mammals, Sestrin 2 binds to leucine and regulates the GATOR2-GATOR1 pathway. In S. cerevisiae, leucine activates TORC1 via Gtr1; however, there is no Sestrin ortholog [76].

In addition to Sestrin 2, S. cerevisiae and mammalian leucyl-tRNA synthetase (LeuRS) have been reported to act as a cytoplasmic leucine sensor to activate TORC1, although the detailed mechanisms on how LeuRS acts in the TORC1 pathway are different between these two species [77-80].

In S. cerevisiae, LeuRS Cdc60 was isolated as a coprecipitating protein with Gtr1 [80]. LeuRS has two functionally separate activities: an essential aminoacylation activity and nonessential amino acid editing activity. A model has been proposed that leucine-bound LeuRS interacts with Gtr1 through the editing domain and positively regulates TORC1.

While the novel function of LeuRS as a leucine sensor is appealing, we have proposed alternative rational models for both S. pombe and S. cerevisiae. We isolated S. pombe ARS mutants, including a LeuRS mutant, during a screening for mutants that phenocopy the TORC1 mutant [20]. In the mutant cells, the expression of tRNA precursors decreases, thereby suggesting a monitoring system that affects the expression of tRNA precursors by checking the subsequent aminoacylation step. We considered that the reduction in tRNA precursors might have caused the downregulation of TORC1, as mentioned above. In S. cerevisiae, in addition to LeuRS, other ARSs, such as HisRS and IleRS, are involved in TORC1 regulation [11]. Therefore, we have proposed the model that uncharged tRNA accumulates in S. cerevisiae ARS mutant cells, and that the accumulated free tRNAs inhibit TORC1 activity. Further studies would reveal similarities and differences in the mode of action of tRNAs in the TORC1 pathway of the two yeast species.

\section{Conclusions}

There is accumulating evidence that tRNAs have more diverse functions than originally thought. For instance, tRNA-derived small RNAs (tsRNAs) have drawn increasing attention; tsRNAs are produced by cleavage at specific sites in tRNAs or pre-tRNAs, and have various biological functions, including the regulation of gene expression, inhibition of translation, prevention of apoptosis, and regulation of epigenetic inheritance. Furthermore, tsRNAs have been demonstrated to be involved in tumorigenesis $[3,6,7,81]$. However, their detailed mechanisms have not been fully understood.

It has long been known that TORC1 regulates tRNA synthesis in downstream events. As we have discussed here, studies over the past few years have uncovered the involvement of tRNA in the regulation of TORC1 activity, in both S. cerevisiae and S. pombe. tRNA is likely to be one of the ideal molecules that transduces nutrient availability, especially for amino acid availability, to TORC1, as it enables the fine-tuned regulation of the TORC1 activity in response to the cellular levels of each of the 20 amino acids. Although, as discussed above, the modes of action of tRNA seem to be different between S. cerevisiae and S. pombe, it is intriguing that tRNA plays important roles in these two evolutionarily distant yeast species. A comparison between the two divergent systems will bring us closer to understanding the novel regulatory mechanisms of TORC1 signaling. Further investigations, not only in yeasts but also in other eukaryotes, would lead us to a comprehensive understanding of the promising tRNA roles in the TORC1 pathway.

Author Contributions: Writing-review and editing, Y.O., Y.K., and A.Y. All authors have read and agreed to the published version of the manuscript.

Funding: This work was supported by the Japan Society for the Promotion of Science KAKENHI, Grant Numbers 19K06649 to Y.O., 19K06668 to Y.K., and 20K06500 to A.Y., by a grant from the Naito Foundation to Y.O., by the joint research program at the Biosignal Research Center, Kobe University (Grant Number: 192001) to Y.O. and A.Y., and by the Joint Research of the Exploratory Research Center on Life and Living Systems (ExCELLS) to Y.O., Y.K., and A.Y. 
Conflicts of Interest: The authors declare no conflict of interest.

\section{References}

1. Liu, G.Y.; Sabatini, D.M. mTOR at the nexus of nutrition, growth, ageing and disease. Nat. Rev. Mol. Cell Biol. 2020, 21, 183-203. [CrossRef] [PubMed]

2. Wullschleger, S.; Loewith, R.; Hall, M.N. TOR signaling in growth and metabolism. Cell 2006, 124, 471-484. [CrossRef] [PubMed]

3. Schimmel, P. The emerging complexity of the tRNA world: Mammalian tRNAs beyond protein synthesis. Nat. Rev. Mol. Cell Biol. 2018, 19, 45-58. [CrossRef] [PubMed]

4. Giege, R. Toward a more complete view of tRNA biology. Nat. Struct. Mol. Biol. 2008, 15, 1007-1014. [CrossRef]

5. Kirchner, S.; Ignatova, Z. Emerging roles of tRNA in adaptive translation, signalling dynamics and disease. Nat. Rev. Genet. 2015, 16, 98-112. [CrossRef]

6. Kim, H.K. Transfer RNA-Derived Small Non-Coding RNA: Dual Regulator of Protein Synthesis. Mol. Cells 2019, 42, 687-692. [CrossRef]

7. Oberbauer, V.; Schaefer, M.R. tRNA-Derived Small RNAs: Biogenesis, Modification, Function and Potential Impact on Human Disease Development. Genes 2018, 9, 607. [CrossRef]

8. Nakashima, N.; Noguchi, E.; Nishimoto, T. Saccharomyces cerevisiae putative G protein, Gtr1p, which forms complexes with itself and a novel protein designated as Gtr2p, negatively regulates the Ran/Gsp1p G protein cycle through Gtr2p. Genetics 1999, 152, 853-867.

9. Binda, M.; Peli-Gulli, M.P.; Bonfils, G.; Panchaud, N.; Urban, J.; Sturgill, T.W.; Loewith, R.; De Virgilio, C. The Vam6 GEF controls TORC1 by activating the EGO complex. Mol. Cell 2009, 35, 563-573. [CrossRef]

10. Sekiguchi, T.; Kamada, Y.; Furuno, N.; Funakoshi, M.; Kobayashi, H. Amino acid residues required for Gtr1p-Gtr2p complex formation and its interactions with the Ego1p-Ego3p complex and TORC1 components in yeast. Genes Cells 2014, 19, 449-463. [CrossRef]

11. Kamada, Y. Novel tRNA function in amino acid sensing of yeast Tor complex1. Genes Cells 2017, 22, $135-147$. [CrossRef] [PubMed]

12. Matsuo, T.; Otsubo, Y.; Urano, J.; Tamanoi, F.; Yamamoto, M. Loss of the TOR kinase Tor2 mimics nitrogen starvation and activates the sexual development pathway in fission yeast. Mol. Cell. Biol. 2007, 27, 3154-3164. [CrossRef] [PubMed]

13. Hayashi, T.; Hatanaka, M.; Nagao, K.; Nakaseko, Y.; Kanoh, J.; Kokubu, A.; Ebe, M.; Yanagida, M. Rapamycin sensitivity of the Schizosaccharomyces pombe tor 2 mutant and organization of two highly phosphorylated TOR complexes by specific and common subunits. Genes Cells 2007, 12, 1357-1370. [CrossRef] [PubMed]

14. Alvarez, B.; Moreno, S. Fission yeast Tor2 promotes cell growth and represses cell differentiation. J. Cell Sci. 2006, 119, 4475-4485. [CrossRef] [PubMed]

15. Uritani, M.; Hidaka, H.; Hotta, Y.; Ueno, M.; Ushimaru, T.; Toda, T. Fission yeast Tor2 links nitrogen signals to cell proliferation and acts downstream of the Rheb GTPase. Genes Cells 2006, 11, 1367-1379. [CrossRef]

16. Weisman, R.; Roitburg, I.; Schonbrun, M.; Harari, R.; Kupiec, M. Opposite effects of tor1 and tor 2 on nitrogen starvation responses in fission yeast. Genetics 2007, 175, 1153-1162. [CrossRef]

17. Kawai, M.; Nakashima, A.; Ueno, M.; Ushimaru, T.; Aiba, K.; Doi, H.; Uritani, M. Fission yeast tor 1 functions in response to various stresses including nitrogen starvation, high osmolarity, and high temperature. Curr. Genet. 2001, 39, 166-174. [CrossRef] [PubMed]

18. Matsuo, T.; Kubo, Y.; Watanabe, Y.; Yamamoto, M. Schizosaccharomyces pombe AGC family kinase Gad8p forms a conserved signaling module with TOR and PDK1-like kinases. EMBO J. 2003, 22, 3073-3083. [CrossRef]

19. Weisman, R.; Choder, M. The fission yeast TOR homolog, tor $1+$, is required for the response to starvation and other stresses via a conserved serine. J. Biol. Chem. 2001, 276, 7027-7032. [CrossRef]

20. Otsubo, Y.; Matsuo, T.; Nishimura, A.; Yamamoto, M.; Yamashita, A. tRNA production links nutrient conditions to the onset of sexual differentiation through the TORC1 pathway. EMBO Rep. 2018, 19, e44867. [CrossRef]

21. Ma, N.; Ma, Y.; Nakashima, A.; Kikkawa, U.; Furuyashiki, T. The Loss of Lam2 and Npr2-Npr3 Diminishes the Vacuolar Localization of Gtr1-Gtr2 and Disinhibits TORC1 Activity in Fission Yeast. PLoS ONE 2016, 11, e0156239. [CrossRef] 
22. Chia, K.H.; Fukuda, T.; Sofyantoro, F.; Matsuda, T.; Amai, T.; Shiozaki, K. Ragulator and GATOR1 complexes promote fission yeast growth by attenuating TOR complex 1 through Rag GTPases. Elife 2017, 6, e30880. [CrossRef]

23. Weisman, R.; Choder, M.; Koltin, Y. Rapamycin specifically interferes with the developmental response of fission yeast to starvation. J. Bacteriol. 1997, 179, 6325-6334. [CrossRef] [PubMed]

24. Otsubo, Y.; Yamamato, M. TOR signaling in fission yeast. Crit. Rev. Biochem. Mol. Biol. 2008, 43, $277-283$. [CrossRef] [PubMed]

25. Doi, A.; Fujimoto, A.; Sato, S.; Uno, T.; Kanda, Y.; Asami, K.; Tanaka, Y.; Kita, A.; Satoh, R.; Sugiura, R. Chemical genomics approach to identify genes associated with sensitivity to rapamycin in the fission yeast Schizosaccharomyces pombe. Genes Cells 2015, 20, 292-309. [CrossRef]

26. Limbach, P.A.; Crain, P.F.; McCloskey, J.A. Summary: The modified nucleosides of RNA. Nucleic Acids Res. 1994, 22, 2183-2196. [CrossRef] [PubMed]

27. Cantara, W.A.; Crain, P.F.; Rozenski, J.; McCloskey, J.A.; Harris, K.A.; Zhang, X.; Vendeix, F.A.; Fabris, D.; Agris, P.F. The RNA Modification Database, RNAMDB: 2011 update. Nucleic Acids Res. 2011, 39, D195-D201. [CrossRef] [PubMed]

28. El Yacoubi, B.; Bailly, M.; de Crecy-Lagard, V. Biosynthesis and function of posttranscriptional modifications of transfer RNAs. Annu. Rev. Genet. 2012, 46, 69-95. [CrossRef]

29. Hopper, A.K. Transfer RNA post-transcriptional processing, turnover, and subcellular dynamics in the yeast Saccharomyces cerevisiae. Genetics 2013, 194, 43-67. [CrossRef]

30. Krutyholowa, R.; Zakrzewski, K.; Glatt, S. Charging the code-tRNA modification complexes. Curr. Opin. Struct. Biol. 2019, 55, 138-146. [CrossRef]

31. Phizicky, E.M.; Alfonzo, J.D. Do all modifications benefit all tRNAs? FEBS Lett. 2010, 584, 265-271. [CrossRef] [PubMed]

32. Boccaletto, P.; Machnicka, M.A.; Purta, E.; Piatkowski, P.; Baginski, B.; Wirecki, T.K.; de Crecy-Lagard, V.; Ross, R.; Limbach, P.A.; Kotter, A.; et al. MODOMICS: A database of RNA modification pathways. 2017 update. Nucleic Acids Res. 2018, 46, D303-D307. [CrossRef] [PubMed]

33. Agris, P.F.; Vendeix, F.A.; Graham, W.D. tRNA's wobble decoding of the genome: 40 years of modification. J. Mol. Biol. 2007, 366, 1-13. [CrossRef] [PubMed]

34. Dauden, M.I.; Jaciuk, M.; Weis, F.; Lin, T.Y.; Kleindienst, C.; Abbassi, N.E.H.; Khatter, H.; Krutyholowa, R.; Breunig, K.D.; Kosinski, J.; et al. Molecular basis of tRNA recognition by the Elongator complex. Sci. Adv. 2019, 5, eaaw2326. [CrossRef] [PubMed]

35. Huang, B.; Johansson, M.J.; Bystrom, A.S. An early step in wobble uridine tRNA modification requires the Elongator complex. RNA 2005, 11, 424-436. [CrossRef] [PubMed]

36. Esberg, A.; Huang, B.; Johansson, M.J.; Bystrom, A.S. Elevated levels of two tRNA species bypass the requirement for elongator complex in transcription and exocytosis. Mol. Cell 2006, 24, 139-148. [CrossRef]

37. Hermand, D. Anticodon Wobble Uridine Modification by Elongator at the Crossroad of Cell Signaling, Differentiation, and Diseases. Epigenomes 2020, 4, 7. [CrossRef]

38. Bauer, F.; Matsuyama, A.; Candiracci, J.; Dieu, M.; Scheliga, J.; Wolf, D.A.; Yoshida, M.; Hermand, D. Translational control of cell division by Elongator. Cell Rep. 2012, 1, 424-433. [CrossRef]

39. Candiracci, J.; Migeot, V.; Chionh, Y.H.; Bauer, F.; Brochier, T.; Russell, B.; Shiozaki, K.; Dedon, P.; Hermand, D. Reciprocal regulation of TORC signaling and tRNA modifications by Elongator enforces nutrient-dependent cell fate. Sci. Adv. 2019, 5, eaav0184. [CrossRef]

40. Goehring, A.S.; Rivers, D.M.; Sprague, G.F., Jr. Urmylation: A ubiquitin-like pathway that functions during invasive growth and budding in yeast. Mol. Biol. Cell 2003, 14, 4329-4341. [CrossRef]

41. Leidel, S.; Pedrioli, P.G.; Bucher, T.; Brost, R.; Costanzo, M.; Schmidt, A.; Aebersold, R.; Boone, C.; Hofmann, K.; Peter, M. Ubiquitin-related modifier Urm1 acts as a sulphur carrier in thiolation of eukaryotic transfer RNA. Nature 2009, 458, 228-232. [CrossRef] [PubMed]

42. Scheidt, V.; Judes, A.; Bar, C.; Klassen, R.; Schaffrath, R. Loss of wobble uridine modification in tRNA anticodons interferes with TOR pathway signaling. Microb. Cell 2014, 1, 416-424. [CrossRef] [PubMed]

43. Bruch, A.; Laguna, T.; Butter, F.; Schaffrath, R.; Klassen, R. Misactivation of multiple starvation responses in yeast by loss of tRNA modifications. Nucleic Acids Res. 2020. [CrossRef] [PubMed] 
44. Reinke, A.; Chen, J.C.; Aronova, S.; Powers, T. Caffeine targets TOR complex I and provides evidence for a regulatory link between the FRB and kinase domains of Tor1p. J. Biol. Chem. 2006, 281, 31616-31626. [CrossRef] [PubMed]

45. Sarkaria, J.N.; Busby, E.C.; Tibbetts, R.S.; Roos, P.; Taya, Y.; Karnitz, L.M.; Abraham, R.T. Inhibition of ATM and ATR kinase activities by the radiosensitizing agent, caffeine. Cancer Res. 1999, 59, 4375-4382. [PubMed]

46. Takahara, T.; Maeda, T. TORC1 of fission yeast is rapamycin-sensitive. Genes Cells 2012, 17, 698-708. [CrossRef]

47. Rallis, C.; Codlin, S.; Bahler, J. TORC1 signaling inhibition by rapamycin and caffeine affect lifespan, global gene expression, and cell proliferation of fission yeast. Aging Cell 2013, 12, 563-573. [CrossRef]

48. Shaheen, H.H.; Hopper, A.K. Retrograde movement of tRNAs from the cytoplasm to the nucleus in Saccharomyces cerevisiae. Proc. Natl. Acad. Sci. USA 2005, 102, 11290-11295. [CrossRef]

49. Takano, A.; Endo, T.; Yoshihisa, T. tRNA actively shuttles between the nucleus and cytosol in yeast. Science 2005, 309, 140-142. [CrossRef]

50. Whitney, M.L.; Hurto, R.L.; Shaheen, H.H.; Hopper, A.K. Rapid and reversible nuclear accumulation of cytoplasmic tRNA in response to nutrient availability. Mol. Biol. Cell 2007, 18, 2678-2686. [CrossRef]

51. Pierce, J.B.; Eswara, M.B.; Mangroo, D. The ins and outs of nuclear re-export of retrogradely transported tRNAs in Saccharomyces cerevisiae. Nucleus 2010, 1, 224-230. [CrossRef]

52. Vannini, A.; Cramer, P. Conservation between the RNA polymerase I, II, and III transcription initiation machineries. Mol. Cell 2012, 45, 439-446. [CrossRef]

53. Graczyk, D.; Ciesla, M.; Boguta, M. Regulation of tRNA synthesis by the general transcription factors of RNA polymerase III-TFIIIB and TFIIIC, and by the MAF1 protein. Biochim. Biophys. Acta (BBA)-Gene Regul. Mech. 2018, 1861, 320-329. [CrossRef] [PubMed]

54. Willis, I.M.; Moir, R.D. Signaling to and from the RNA Polymerase III Transcription and Processing Machinery. Annu. Rev. Biochem. 2018, 87, 75-100. [CrossRef] [PubMed]

55. Moir, R.D.; Willis, I.M. Regulation of pol III transcription by nutrient and stress signaling pathways. Biochim. Biophys. Acta (BBA)-Gene Regul. Mech. 2013, 1829, 361-375. [CrossRef] [PubMed]

56. Michels, A.A. MAF1: A new target of mTORC1. Biochem. Soc. Trans. 2011, 39, 487-491. [CrossRef]

57. Zhang, S.; Li, X.; Wang, H.Y.; Zheng, X.S. Beyond regulation of pol III: Role of MAF1 in growth, metabolism, aging and cancer. Biochim. Biophys. Acta (BBA)-Gene Regul. Mech. 2018, 1861, 338-343. [CrossRef]

58. Pluta, K.; Lefebvre, O.; Martin, N.C.; Smagowicz, W.J.; Stanford, D.R.; Ellis, S.R.; Hopper, A.K.; Sentenac, A.; Boguta, M. Maf1p, a negative effector of RNA polymerase III in Saccharomyces cerevisiae. Mol. Cell. Biol. 2001, 21,5031-5040. [CrossRef]

59. Upadhya, R.; Lee, J.; Willis, I.M. Maf1 is an essential mediator of diverse signals that repress RNA polymerase III transcription. Mol. Cell 2002, 10, 1489-1494. [CrossRef]

60. Moir, R.D.; Lee, J.; Haeusler, R.A.; Desai, N.; Engelke, D.R.; Willis, I.M. Protein kinase A regulates RNA polymerase III transcription through the nuclear localization of Maf1. Proc. Natl. Acad. Sci. USA 2006, 103, 15044-15049. [CrossRef]

61. Oficjalska-Pham, D.; Harismendy, O.; Smagowicz, W.J.; de Peredo, A.G.; Boguta, M.; Sentenac, A.; Lefebvre, O. General repression of RNA polymerase III transcription is triggered by protein phosphatase type 2A-mediated dephosphorylation of Maf1. Mol. Cell 2006, 22, 623-632. [CrossRef]

62. Roberts, D.N.; Wilson, B.; Huff, J.T.; Stewart, A.J.; Cairns, B.R. Dephosphorylation and genome-wide association of Maf1 with Pol III-transcribed genes during repression. Mol. Cell 2006, 22, 633-644. [CrossRef]

63. Huber, A.; Bodenmiller, B.; Uotila, A.; Stahl, M.; Wanka, S.; Gerrits, B.; Aebersold, R.; Loewith, R. Characterization of the rapamycin-sensitive phosphoproteome reveals that Sch9 is a central coordinator of protein synthesis. Genes Dev. 2009, 23, 1929-1943. [CrossRef] [PubMed]

64. Lee, J.; Moir, R.D.; Willis, I.M. Regulation of RNA polymerase III transcription involves SCH9-dependent and SCH9-independent branches of the target of rapamycin (TOR) pathway. J. Biol. Chem. 2009, 284, 12604-12608. [CrossRef] [PubMed]

65. Shor, B.; Wu, J.; Shakey, Q.; Toral-Barza, L.; Shi, C.; Follettie, M.; Yu, K. Requirement of the mTOR kinase for the regulation of Maf1 phosphorylation and control of RNA polymerase III-dependent transcription in cancer cells. J. Biol. Chem. 2010, 285, 15380-15392. [CrossRef] [PubMed]

66. Michels, A.A.; Robitaille, A.M.; Buczynski-Ruchonnet, D.; Hodroj, W.; Reina, J.H.; Hall, M.N.; Hernandez, N. mTORC1 directly phosphorylates and regulates human MAF1. Mol. Cell. Biol. 2010, 30, 3749-3757. [CrossRef] 
67. Kantidakis, T.; Ramsbottom, B.A.; Birch, J.L.; Dowding, S.N.; White, R.J. mTOR associates with TFIIIC, is found at tRNA and 5S rRNA genes, and targets their repressor Maf1. Proc. Natl. Acad. Sci. USA 2010, 107, 11823-11828. [CrossRef] [PubMed]

68. Wei, Y.; Tsang, C.K.; Zheng, X.F. Mechanisms of regulation of RNA polymerase III-dependent transcription by TORC1. EMBO J. 2009, 28, 2220-2230. [CrossRef]

69. Du, W.; Halova, L.; Kirkham, S.; Atkin, J.; Petersen, J. TORC2 and the AGC kinase Gad8 regulate phosphorylation of the ribosomal protein $\mathrm{S} 6$ in fission yeast. Biol. Open 2012, 1, 884-888. [CrossRef]

70. Sanchez-Casalongue, M.E.; Lee, J.; Diamond, A.; Shuldiner, S.; Moir, R.D.; Willis, I.M. Differential phosphorylation of a regulatory subunit of protein kinase CK2 by target of rapamycin complex 1 signaling and the Cdc-like kinase Kns1. J. Biol. Chem. 2015, 290, 7221-7233. [CrossRef]

71. Lee, J.; Moir, R.D.; McIntosh, K.B.; Willis, I.M. TOR signaling regulates ribosome and tRNA synthesis via LAMMER/Clk and GSK-3 family kinases. Mol. Cell 2012, 45, 836-843. [CrossRef] [PubMed]

72. Chymkowitch, P.; Nguea, P.A.; Aanes, H.; Robertson, J.; Klungland, A.; Enserink, J.M. TORC1-dependent sumoylation of Rpc82 promotes RNA polymerase III assembly and activity. Proc. Natl. Acad. Sci. USA 2017, 114, 1039-1044. [CrossRef] [PubMed]

73. Filer, D.; Thompson, M.A.; Takhaveev, V.; Dobson, A.J.; Kotronaki, I.; Green, J.W.M.; Heinemann, M.; Tullet, J.M.A.; Alic, N. RNA polymerase III limits longevity downstream of TORC1. Nature 2017, 552, $263-267$. [CrossRef] [PubMed]

74. Laor, D.; Cohen, A.; Kupiec, M.; Weisman, R. TORC1 Regulates Developmental Responses to Nitrogen Stress via Regulation of the GATA Transcription Factor Gaf1. MBio 2015, 6, e00959. [CrossRef]

75. Rodriguez-Lopez, M.; Gonzalez, S.; Hillson, O.; Tunnacliffe, E.; Codlin, S.; Tallada, V.A.; Bahler, J.; Rallis, C. The GATA Transcription Factor Gaf1 Represses tRNAs, Inhibits Growth, and Extends Chronological Lifespan Downstream of Fission Yeast TORC1. Cell Rep. 2020, 30, 3240-3249. [CrossRef]

76. Gonzalez, A.; Hall, M.N. Nutrient sensing and TOR signaling in yeast and mammals. EMBO J. 2017, 36, 397-408. [CrossRef]

77. Duran, R.V.; Hall, M.N. Leucyl-tRNA synthetase: Double duty in amino acid sensing. Cell Res. 2012, 22, 1207-1209. [CrossRef]

78. Segev, N.; Hay, N. Hijacking leucyl-tRNA synthetase for amino acid-dependent regulation of TORC1. Mol. Cell 2012, 46, 4-6. [CrossRef]

79. Han, J.M.; Jeong, S.J.; Park, M.C.; Kim, G.; Kwon, N.H.; Kim, H.K.; Ha, S.H.; Ryu, S.H.; Kim, S. Leucyl-tRNA synthetase is an intracellular leucine sensor for the mTORC1-signaling pathway. Cell 2012, 149, 410-424. [CrossRef]

80. Bonfils, G.; Jaquenoud, M.; Bontron, S.; Ostrowicz, C.; Ungermann, C.; De Virgilio, C. Leucyl-tRNA synthetase controls TORC1 via the EGO complex. Mol. Cell 2012, 46, 105-110. [CrossRef]

81. Xie, Y.; Yao, L.; Yu, X.; Ruan, Y.; Li, Z.; Guo, J. Action mechanisms and research methods of tRNA-derived small RNAs. Signal. Transduct. Target. Ther. 2020, 5, 1-9. [CrossRef] [PubMed]

(C) 2020 by the authors. Licensee MDPI, Basel, Switzerland. This article is an open access article distributed under the terms and conditions of the Creative Commons Attribution (CC BY) license (http://creativecommons.org/licenses/by/4.0/). 